\title{
Retirement perception and workers' behavior: a comparative study between workers of the public and private sectors of some selected enterprises in the Bamenda Municipality
}

\author{
${ }^{1}$ Patrick Kongnyuy \\ Faculty of Education, the University of Bamenda \\ ${ }^{2}$ Nsairun Leonard Yuyun \\ The University of Bamenda
}

\begin{abstract}
Many employees often approach retirement with mixed feelings as they exit service. To many, it represents a transition from the known to the unknown. After retirement, income becomes irregular and financial expectations become less visible. This is because policies are not well implemented to the letter, leaving retirees' lives hanging in the balance in their old age. Management of life after retirement entails planning for the unpredictable and unavoidable new lifestyle when one is still in active service. This study was aimed at assessing the retirement perception of workers of the public and private sector in Bamenda Municipality and their consequent economic and social behavior towards the concept of retirement.The study employed an Ex post facto research design with a sample of 400 working individuals ranging from the ages of 30 to 60 years that were randomly selected. A questionnaire and interview guide were the instruments used to collect data for the study. Responses revealed that retirement age perception $(\mathrm{F}=32.56, \mathrm{df}=398, \mathrm{P}<0.01)$, pre- counselling $(\mathrm{F}=46.64, \mathrm{df}=398, \mathrm{P}<0.01)$ and post counseling services $(\mathrm{F}=36.13, \mathrm{df}=398, \mathrm{P}<0.01)$ significantly predicted workers' behavior. The findings revealed an important level of misunderstanding of what retirement is all about. Potential conflict in retirement, knowledge, planning, attitude toward retirement and retirement goal clarity are the significant predictors of retirement social and economic behavior.
\end{abstract}

Key words: Retirement, pre-retirement, post-retirement, perception, workers' behavior, enterprises, post counselling services.

DOI: $10.7176 / \mathrm{JEP} / 11-27-16$

Publication date:September $30^{\text {th }} 2020$

Introduction and the Problem

The concept of retirement is an act of leaving one's job, career, or occupation permanently, as a result of age, legal number of years spent on service or on the grounds of ill health or accident. The notion of retirement means different things to different people. While some view it from the positive point of view and awaits it with joy, others have a negative perception of retirement and associate it with a period of boredom, economic hardship and death. Such people experience a sense of isolation and loss of status. Retirement like death is an obligatory end which every worker must pass through whether in the private sector or public sector (Onoyas, 2013). For Akinade (2006), retirement is a real end unavoidable end to the worker's career. It refers to the eventual end of an employee's primary job. A person may also retire by reducing work hours. Aigbekaen \& Egharevba (2008) defined retirement as a total withdrawal of an employee's service form the organization after putting in some specified number of years or having reached a specified retirement age. The psychological implications of retirement are numerous.

Deciding when to retire may be one of the most important decisions an individual makes during his or her lifetime. Although the retirement decision occurs late in life, it can significantly affect an individual's well-being for many years. No matter what may prompt a worker's retirement, the perception of retirement and the role of management have in recent years become a major concern in Industrial and Organizational Psychology. Over the past ten years, the management of public and private organizations have turned their attention towards helping aging workers to prepare for retirement and to making the retirement years a "true" period of rest. Public and private organizations with the control and supervision of the National Social Insurance Fund (CNPS) have assumed an increasingly active role in helping workers (employed or self-employed) to plan for their retirement and to achieve pre and post retirement satisfaction.

This is obtained through counseling sessions and adult education programs. There are also many formal and informal programs designed to assist employees with their retirement planning worldwide. No matter the assistance given to the worker to prepare for his/her retirement years, the question remains how different workers perceive the reality of retirement and how they behave towards it. 
The term retirement generally connotes a complete and permanent withdrawal from paid labor, and entering retirement is often thought of as an abrupt change in the life of an elderly worker. This conception of retirement accurately reflects the experience of most workers today. Although some retired workers do switch to part-time work at the end of their careers (Ogungbcuin, 2003). Cooper (1993) confirmed that about 75 percent of all retirement cases today are transitions from a full-time job to being part time jobs. But we cannot be certain that defining retirement as a departure from full time job, regardless of the number of years worked, captures the meaning that the term had in the past. In the past men may have been more likely to face work out of their lives slowly. Historians of New England colonial economies found that older property owners remained closely involved in farming or preindustrial enterprises, supervising the family members and others who provided the labor supply. The continued importance of farming and of artisanal enterprises to the American economy may have allowed owners to reduce hours of work and continue to operate their enterprises with the help of family members and hired labour (Dora, 2008).

Moreover, many people will use the terms "financial independence" alongside "retirement," because one cannot exist without the other. Both statues are achieved when you have garnered enough investments, savings funds, and pension income to cover whatever living expenses you have. In short, when you retire, work isn't something you have to do to survive. The transition from work to retirement is one of the most demanding during lifespan. Hence, a great importance so that aging workers should be able to make informed choices regarding retirement and to maintain quality of life before and after leaving the workforce.

Retirement is not thus a destination but the beginning of a new journey accompanied with Psychological impacts. Regular, proper monitoring and rebalancing of the retirement plan is very important because such a transition maybe viewed not only as a change in role but also as an expression of a redefinition of previous career role. Career roles are associated with status, identity, power, and money. This transition could be seen as a period of crisis as seen (Sinick, 1977). The stage of retirement requires serious adjustment in the live style identity, interpersonal relationships, and social roles. Furthermore, people's reasons may bring out their feelings towards this transition and in turn their feelings may influence their behaviors. Counselling can help to confront and struggle with developmental tasks such as choosing a second career if needed, addressing death, and accommodating retirement (Sinick, 1977). Atchley (1975) opined that there is a need for career counselling specialists to work with retired workers. He highlights the importance of techniques designed to be responsive to retirees' particular needs.

According to the Burgess's activity theory by Tensley and Tenstey (1987), individuals with a large number of roles are believed to be better equipped to cope with the loss of single role and interpersonal activity which is regarded as a key feature of successful retirement. New activities tend to compensate for roles that are lost as the individual ages, while leisure values tend to replace work values in maintaining activity level. This theory is relevant to this study because it shows that an individual who suffers a job loss will seek to find a substitute role to keep active which is in line with what pre-retirement counseling is all about. Without activity, the human machine remains unexploited, unchallenged and deteriorates faster than it should. Bell (1975) explain the view of the activity theory that activity in retirement is good because it delays mental and physical deterioration. They also agree that people who actively participate in social activities outside their work feel happy, and can function in activity till very late in life, barring inability that results from senility. They agree that social participation and interaction as a way of life is not affected by retirement. Therefore, workers who had active social lives would continue to do so in retirement. They would likely have a more satisfactory post-retirement period. Every worker has to find his/her way through old age to retirement.

The continuity theory by Atchley (1989) suggests that people are essentially the same throughout life in psychological terms. They observe the same preferences, the same conduct patterns or the same social environment throughout life. If an individual was very active as a child, it is likely that this level of activity will be retained on condition that the corresponding state of health makes it possible. As a result, those workers who were active during their pre-retirement life will look for ample opportunities even after their retirement. Life is based on the premise that older adults who preserve a similar lifestyle in retirement as they previously had will have a higher level of psychological well-being (Atchley, 1989). According to Feldman and Beehr (2011), bridge employment among other gradual transitions into retirement helps older adults to maintain structure and their selfimage through meaningful activities. Specifically, research on bridge employment validates the basic views of continuity theory in that individuals who enjoy their work or succeed in their careers tend to choose same-career bridge employment whereas other-field bridge employment often occurs in response to job strain (Gobeski \& Beehr, 2008). Unlike the abrupt transition associated with disengagement theory, continuity theory recognizes the 
disadvantages of a complete cessation from work without having other aspirations. Therefore, this model addresses retirement as a stage of life and recognizes that well-being is connected to balancing work and life satisfaction. Wilson \& Aggrey (2015) argued that retirement savings are important as retirement is an essential transition in life which comes with challenges of adjustment and changes in lifestyle, self-esteem, friendships and vacation. Atchley (1998) opined that retirement does not occur suddenly in one's working life; instead, it involves a series of steps to be taken by an individual during the active working years. According to Wilson \& Aggrey (2012), any worker who enters employment has a certainty that one day he or she will grow old and when the aging process begins, there will come a time the worker will be called to retire from active service. Atchley (1998), stated that it is essential to counsel workers to that fact of life about retirement income. According to the author, the counseling will be best for those entering the job. Moreover, in preparation for retirement, the enterprise should alert workers to the financial security, health and lifestyle of retirement early enough to be effective.

Management and personnel management policies, especially those inspired by neoclassical economic models, do not esteem older worker ( 55 - 65 years) productivity in positive terms. Obimba (2005) acknowledges that some stereotypical conceptions about older workers are responsible for specific management choices; for example, professional training for older workers is not valued a profitable investment. As Noone (2010) underlines, a wide literature has not confirmed at all a lot of prejudicial instances, established upon the existence of a direct causal correlation between retirement and age.

Hansson et al. (1997) argued retirement is rarely based on one influence alone, but that several variables affect the decision. Employers contribute to these perceptions by their offering, or not, suitable employment, and governments also contribute with policies and incentives concerning age pension benefits. Parnes and Sommers (1994) described some older workers who trusts in their good health, continued psychological commitment to work, and dislike of retirement.

By introducing age as an independent variable, we try to understand with it that when faced with retirement decision it is important to know which generation one belongs. We try to understand whether there is a relation between retirement age and the social and economic behavior of workers, thus our first and second hypothesis based behavior in the pre and post retirement ages.

\section{Methodology}

The study adopted the survey and Ex post facto designs. The survey research design was adopted because of its cost and time efficiency. It enables the researcher to use part of the study population to generalize the result on the whole population. Ex post facto design seeks to establish cause effect relationships. With the Ex post facto, the cause and effect relationship between the retiree's age and economic and social behavior was established.

The sample size consisted of 213 workers working in the public services and 187 workers of the private sector, giving a total of 400 workers. These workers were sampled using the simple random sampling technique. Judgmental sampling technique was equally used to select managers for our interview guide.

The purposive and the random sampling methods were used in selecting the future retirees as sample of the study. The random sampling technique was chosen to select 400 workers from 1200 workers. This sample is appropriate according to Kcrejcie \& Morgan (1970). The purposive sampling technique was used because we targeted only the working class and purposefully doing white-collar jobs.

\section{Method of data analysis}

Descriptive and inferential statistics were used for data analysis. The respondents were to rate on a four point likert scale as follows; strongly agree (SA), Agree (A), Disagree (D) and Strongly Disagree (SD). This was done after reversing responses on questions which were made negative. Concerning the descriptive statistics, percentages, frequency tables and charts were used. For inferential statistics, linear regressions and an independent sample ttest were used to verify the hypotheses at the significance level of 0.05 . 
Findings

Table 1: Summary of Findings

\section{Hypotheses}

$\mathrm{H}_{\mathrm{O}} 1$ :There is no significant relationship between retirement age and workers' behavior of both the private and public sector

$\mathrm{H}_{\mathrm{O}} 2$ :There is no significant difference in the retirement perceptions between workers of public sector and those of the private sector

$\mathrm{H}_{\mathrm{O}} 3$ : There is no significant 0.42

\section{Coef. of p-value Decision Regressio}

n

0.37

$t=-0.36$

relationship between Pre counseling services and worker behavior in both the private and public sector
.000

72

(n)
retained
Null hypothesis rejected and the alternative hypothesis retained

Null hypothesis retained.
There is a significant relationship between retirement age and workers' behavior of both the private and public sector

There is no significant difference in the retirement perceptions between workers of public sector and those of the private sector

$0.000 \quad$ Null hypothesis rejected and the alternative hypothesis

$0.000 \quad$ Null hypothesis rejected and the alternative hypothesis retained
There is a significant relationship between Pre counseling services and worker behavior in both the private and public sector
There is a significant relationship between Post counseling services and worker behavior in both the private and public sector
$\mathrm{H}_{\mathrm{O}} 4$ : There is no significant 0.038 relationship between Post counseling services and worker behavior in both the private and public sector

\section{Discussion}

\section{Pre and post retirement programs available for workers}

Finding shows that there are little or no pre and post retirement programs available for workers in both the public and private. Although there is a growing interest in pre-retirement planning, the fact remains that comprehensive programs of this type are not generally being provided to the great majority of our older workers today. Some form of individual counseling is the approach-taken by the majority of firms, and in general, these sessions are held very close to the individual's actual retirement date and fall drastically short of providing him with the assistance necessary to help reach a successful adjustment to retirement.

The study of Lusardi and Mitchell (2006) noted in this aspect that workers are poorly informed about financial products and practices which may stunt their ability to save and invest for retirement, thus undermining their wellbeing in old age. This financial illiteracy may render workers more vulnerable to economic and social hardship during retirement. Noone, Stephens, \& Alpaa, (2010), suggested that if workers while still at service benefit from financial strategies put at their disposal, they will look forward to an exciting, meaningful and successful retirement life while Appiah - Asong (2014) concluded that workers who have attended retirement planning seminars have positive attitude towards retirement compared to those who have never participated in any program.

This implies that good planning and counseling programs will help retirees to prepare well towards their retirement and have a comfortable and less stressful life during their retirement as well as develop a positive perception of retirement.

The extent to which retirement perception can influence the social behavior of workers

The finding indicates that workers of both sectors of the economy no matter the age and longevity perceive retirement negatively because of fear poor social relationships that may occur during retirement. Bal et. al., (2011) meta-analysis presents the last few decades of research on the perceptions of older workers, and suggests that these perceptions include both positive and negative assumptions. 
A wish to meet and make friends, feelings of loneliness and boredom, a need to get away from children and/or relatives/ neighbors were mentioned by a little over one/third of the respondents $(\mathrm{N}=163)$ as factors that caused most workers to prefer work than going on retirement.

Past research has supported the finding that workers to overcome boredom and loneliness by post ponding retirement (Atchley and Cobert, 1977; Sobol, 1974; Szinovacz, 1973). The inclusion of the item "to get away from children, relatives and/or neighbors" into the same response category, perhaps may have been the reason for the small percentage that responded negatively to the question. "It will be difficult to live with people you have not been with for long" Their negative perception of retirement comes from issues ranging from: inadequate social preparation, lack of proper understanding of what retirement is all about, long bureautic process in obtaining retirement benefits, difficult adjustment to retirement, trouble finding leisure activities during retirement.

Hence, this study found that aging employees developed and sustained some expectations, opportunities, confusion and misconception in their mind right before their retirement.

\section{The extent to which retirement perception can influence the economic behavior of workers}

When individuals decide to stop working, they must have a way to support themselves financially, as their income from work will no longer be available. Thus, the question of how to support oneself in retirement was an important consideration in objective three and in the retirement decision at large. Traditionally, income during retirement is thought to come from three main sources, or what is generally referred to as a "three-legged financial stool": Social Security benefits, pensions, and personal savings. Unfortunately, many workers fail to consider the issue of financial well-being in retirement until retiring becomes imminent (EBRI 2008), with the vast majority of retirees planning to postpone retirement.

Similarly, employees' perceptions of autonomy in deciding when to retire predicted a significant dependence on their level of financial security, as well as their perceptions about the type of organizational policies and practices that are available to them (such as whether the organization allows retirees to work part-time). This finding supports other research, which found that low autonomy in job tasks income security lead to a negative perception and poor altitude towards retirement (Blekesaune \& Solem 2005). This alone shows that financial resources are important in the retirement decision (Phillipson 2004). The preference for postponing retirement is related to chronological age and perception of income adequacy, but also to work variables (work importance, firm policies supporting aged employees) and attitudes to retirement.

The perception of retirement for workers of the private and the public sector

The study reveals that both workers of the public and private sectors approach retirement with mixed feelings and perceived it negatively. Policies on retirement are not well defined and implemented. To this end many workers agreed that retirement was not necessary at the age prescribed by the law. They prefer an increase in the retirement age as it will help the pensioner to gain salary so that they can still support their family as the cost of living today increased tremendously. In relation to this preference to increase retirement age, for $65 \%$, of workers, it is too early for one to retire at 55 especially. This is one of the reasons why Morrish (20011) requested for the new age of retirement to secure the welfare of the aging workers. There are only $28 \%$ of workers in both sectors that save regularly for their retirement plan at the economic and social levels. However, for the rest (72\%), retirement planning is more dependent on the financial factors as compared to the social and psychological factors.

The effect of pre and post counseling on workers social and economic behavior.

The finding revealed that giving all employees access to a free, confidential, workplace counselling service can significantly influence their economic and social behavior. The findings of Laudi \& Mitchelle (2006) revealed this fact. "financial education and counseling for retirees has a strong effect on retirement saving decision" The results of Kajauchire, (2015) who conducted a study on retirement planning behavior and counseling on middle- and highincome earners in south Africa revealed that behavioral factors significantly relate to retirement planning.

We out that those workers who retired early, the importance of pre counseling was indicated by the fact that retirees who received counseling were found to like to relate well with their relatives after retirement than those who did not receive any counseling. Findings of this study also showed the importance of making retirement plans before deciding to retire rather that after retirement. More than 70 percent of both of both worker of the public and private sectors who scored high on the adjustment scale had made economic and social plans for their retirement. 
It is not about giving advice, but about providing a non-judgmental, empathic and accessible means to allow an employee to find a way forward in their social and economic behavior before and after retirement. One question of concern was the age at which to begin retirement preparation education. Our study revealed no single best answer. There was almost unanimous agreement by the respondents that most workers need to plan for their retirement. However, they were of much less agreement in their perceptions as to those responsible for providing preretirement planning assistance. It has been reported that two years prior to the company's compulsory retirement age is not early enough. Others have indicated at least three years before the average early retirement age, while some companies start their retirement preparation work at age 40 "Some experts suggest that ten years before retirement is not too soon to begin planning for it. However, the Drake Pre-retirement Planning Center determined that the age group of 50-55 shows the greatest positive attitude change toward retirement after participating in a pre-retirement planning program.

\section{Conclusion}

The profile of the respondents was all inclusive as all ages were well represented. In addition, the gender of the respondents was fairly distributed though there were more female than male respondents in both sectors. Further, all levels in the organizational structure were well represented. All the respondents were members of welled structured organization and therefore aware of the retirement policies. It is clear from the responses that employees in private Sector pension schemes were heavily affected by the negatively of retirement perception as compared to those of the private sector.

In addition, the consequent economic and social behavior remains the same for all workers as retirement planning is more dependent to the financial factors as compared to the social and psychological factors. Notwithstanding the fact that the retirement policies are more of a Government directive, the information on these policies was to a moderate extent disseminated to employees in the Public Sector than in the private sector. The information relayed to the employees gave them a moderate understanding of the pension scheme and its benefits. However, in spite of the information given, employees in the Public sector pension schemes still felt that the retirement is good for them only to a little extent.

The contributions and benefits of the employees in both sectors were affected by their positive or negative perception of retirement. Hence those who view retirement negatively see these contributions as punishment or fines while those who view positively view it as investment. It is clear from the analysis that the negative attitude and perception of retirement is due the long bureaucratic process in obtaining benefits at retirement.

\section{REFERENCES}

Aigbekaen \& Egharevba, O. (2008). The counsellor's role in pre-retirement education in Nigeria. p53.

Akinade, F. A. (2006). Towards Successful Retirement \& Joyful Retirement. Lagos: Olu Akin.

Akinade, E. A. (2006). Towards successful and joyful retirement. Ibadan: Olu-Akin.

Appiah - Asong, J. (2014). The influence of retirement planning and attitude towards retirement among employees of selected Ghanaian Organizations. Accra: PB Press.

Atchley, R, C.and S. L. Corbett (1977) "Older women and jobs." Pp. 121-125 in Lillian Troll, J. Israel and K. Israel (eds.), Looking Ahead. Englswood Cliffs, N.J.: Prentice Hall.

Atchley, R. (1975) Adjustment to loss of Job at Retirement. The International journal of Aging and human development.

Atchley, R. (1989) A continuity theory of normal ageing; The Gerontologist, 29(2); 183-190.

Atchley, R. (1998) The effect of age, retinal eccentricity, and speed on the detection of optic flow components. Psychology and Aging, 13(2), 297-308.

Bal, P. M., de Lange, A. H., Ybema, J., Jansen, P. G. W., \& van der velde, M. E. G. (2011). Age and trust as moderators in the relationship between procedural justice and turnover: A large-scale longitudinal study. Applied Psychology: An International Review, 60, 66-86.

Bell, T. H. (1975) Topographically generated internal waves in the open ocean. Journal of Geophysis Reswarch. 80(3); 1896-1999.

Blekesaune, M. \& Solem P. E. (2005). Working conditions and early retirement: A prospective study of retirement behavior. Research on Aging, 27 (1), pp. 3-30.

Cooper, D. F. (1993). Retirement style, post-retirement work pattern and retirement

Feldman, D. C. and Beehr, T. R. (2011), A Three-phase Model of Retirement Decision making, American Psychologist. 66 (3); 193-203. 
Gobeski,K.T.,\& Beehr,T.A.(2008) How retirees work: predictors of different types of bridge employment. Journal of Organizational Behavior. ;30(3):401-425.

Hansson, R.O., DeKoekkoek., P.D, Neece, W.M., \& Patterson, D.W. (1997). 'Successful aging at work: Annual Review, 1992-1996: The older worker and transitions to retirement', Journal of Vocational Behavior, 51, pp. 202-233.

Kajauchire, M. (2005). Retirement planning behavior of middle-and high-income earners in South Africa.

Lusardi, A. \& Mitchell, O. S. (2006). Financial literacy and retirement preparedness: evidence and implications for educational financial programs

Morrish, A.H. (2001) The Physical Principles of Magnetism. IEEE Press, Piscataway

Noone, J. H., Stephens, C., \& Alpass, F. (2010). The process of retirement planning scale: Development and validation. Psychological Assessment, 32, 715-739.

Obimba, F.V. (2005). Anxiety over the uncertainties of life in retirement: Implication for counseling. The counselor, 16 (1) $184-193$.

Ogungbemi, O. (2003). The challenge of retirement. Ibadan: Dan Jones IRWIN, Whiney Communication.

Onayas, A. (2013). Financial planning strategies towards retirement as perceived by potential retirees in Universities of Niger Delta, Nigeria. International Journal of Business and social science., Vol. $4(140.256$.

Onoyase, D. (2013). Financial planning strategies toward retirement as perceived by potential retirees in universities in the Niger Delta. Journal of Education and Practice, 4, 14.

Parnes, H \& Sommers, D. (1994). 'shunning retirement: Work experience of men in their seventies and early eighties’, Journal of Gerontology: Social Sciences, 49, pp. S117-S124.

Phillipson, C. (2004), 'Work and retirement transitions: Changing sociological and social policy contexts', Social Policy and Society, Vol. 3, No. 2, pp. 155-162.

Sinick, D. (1977). Sinickal Synopses; The personnel and Guidance Journal, 56(1).

Sobol, M. G. (1974) Committment to work. Pp. 63-80 in L. W. Hoffman and P. I. Nye (eds.). Working Mothers. San Francisco: Jossey-Bass.

Szinovacz, M. E. (1973) "Satisfaction with work, marriage and household activities in women blue collar and white-collar workers." Paper presented at the meeting of the international Society for the Study of Behavioral Development, Ann Arbor, Michigan.

Tensley,H. E. and Tenstey, D. J. (1987). Uses of factor analysis in counselling psychology research. Journal of Counselling Psychology, 34(4), 414.

Wilson, k, N., \& Aggrey, E. A. (2012). Retirement planning and counselling: Issues and challenges for teachers in public schools in the Sekonde circuit US-China Wducation Review, A8755-767. 